\title{
PHILCOXIA:
}

\section{A NEW GENUS OF CARNIVOROUS PLANT}

Andreas Fleischmann • University of Munich, LMU • Department of Systematic Botany and Mycology

• Menzinger Strasse 67•80638 Munich•Germany•fleischmann@lrz.uni-muenchen.de

Keywords: Philcoxia, Brazil.

Philcoxia P.Taylor \& V.C.Souza is a genus of three small, rare, enigmatic plant species from Brazil. This fairly new plant genus was first described to science in 2000 by Peter Taylor and co-workers, and consists of the species Philcoxia bahiensis from Bahia, P. goiasensis from Goiás, and P. minensis from Minas Gerais, each named for the Brazilian state to which it is endemic (Taylor et al. 2000). All species of Philcoxia are characterized by thickened subterranean stems that bear small and lax rosettes of tiny peltate leaves on very long petioles (see Fig. 1). The minute leaves, only 1-3 $\mathrm{mm}$ in diameter, are lined with stalked, sticky glandular hairs on their upper surface and lie flat on the ground, usually covered by a thin layer of sand grains. Although two of the species were presumed to be annuals by Taylor et al. (2000), more recent collections show that all of them posses a well-developed underground stem, and are thus certainly perennials (probably even very long-lived). The erect inflorescence can reach up to $c a .30 \mathrm{~cm}$ tall, it is many-flowered and multiply-branched, the lilac to purple flowers consisting of a tubular corolla are vaguely reminiscent of flowers of Lentibulariaceae (see Fig. 2).

All three species of Philcoxia exclusively grow in a very unique habitat of the Brazilian cerrado scrublands or campos rupestres vegetation ("rocky fields", an open vegetation type of nutrient-poor sandstone-based soils), namely in open plain patches consisting of deep, bare, white silica sand (see Fig. 3).These deep sand patches are well drained, and thus remain very dry for most of the year. They only seem to be moist during the rainy season, when constantly water-fed by rainfall. During the dry season, the uppermost few millimetres of this substrate consist of a hardened, but fragile crust of baked sand grains, glued together by cohesion. It is underneath or within this thin layer, where the leaves of Philcoxia are found, protected from intense radiation and heat, and where they might receive some moisture from nocturnal condensation. Only few plants are able to survive in these exposed and inert sand patches, accompanying Philcoxia - mainly few globose cacti of the genus Melocactus, and annual Eriocaulaceae (pipeworts), both which are mainly found at the margins of the sand pits. Philcoxia, however, is perfectly adapted to this extreme habitat, by forming thickened, very long, tap-root like rhizomes, which serve as storage organs (and which may reach some moisture in deeper soil layers), and small subsoil leaves to minimize evaporative loss of water. Only the comparatively tall, branched inflorescences are produced above the soil surface, and scapes of many individuals are usually sticking out of the sand well spaced from each other, but in great numbers (see Fig. 3). Although Philcoxia is really rare and localized across Brazil, only known from a handful of small restricted sites, it is usually dominating the centers of the sand plain habitats where it occurs. Nevertheless all three species can be considered as endangered, as their habitats are under threat of human development, and most of the sand pits where they occur are exploited by mining companies.

\section{Proof of carnivory}

Large numbers of dead nematodes or their chitin cuticles have been found adhering to the glandular leaves of herbarium specimens of Philcoxia, along with numerous sand grains (Fritsch et al. 2007; Pereira \& Oliveira 2010). Although Taylor et al. (2000) initially doubted 

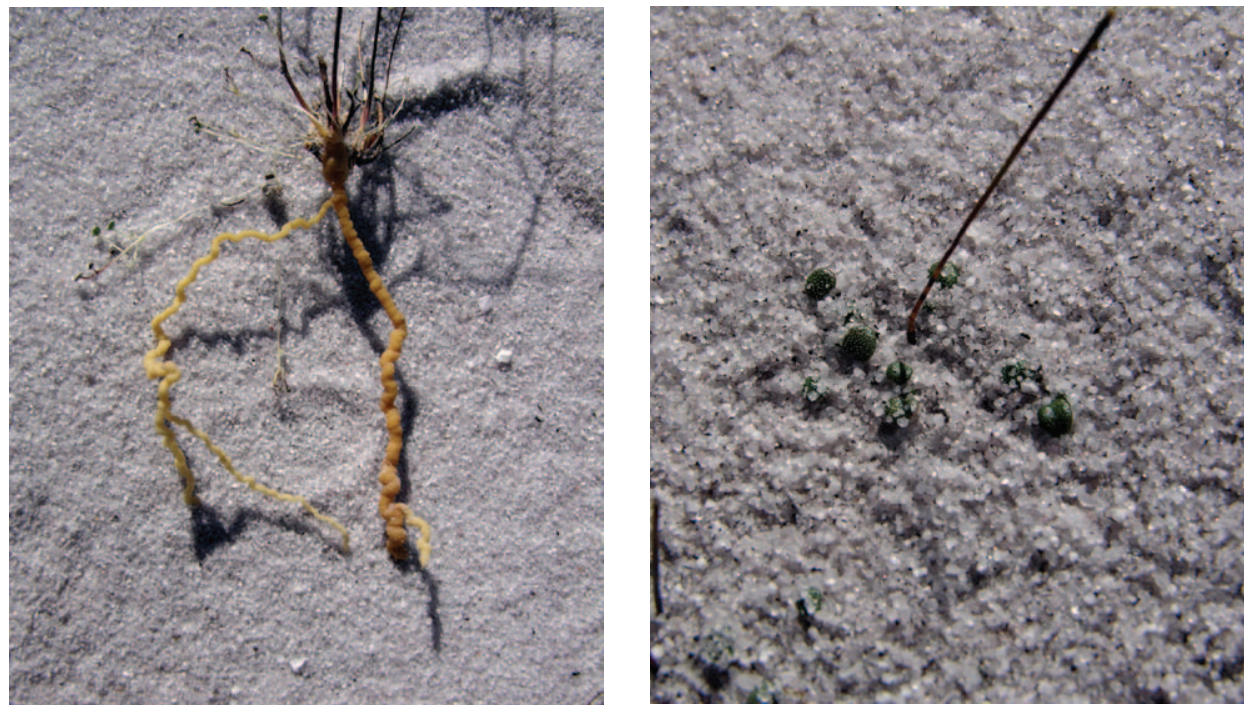

Figure 1: (Left) Partially excavated plant of Philcoxia minensis, illustrating only the uppermost part of the extensive underground system. Note the pale brownish, thick stem, which is proportionally large compared to the small rosettes of leaves, which are borne on long pale-whitish petioles and stolons. (Right) The small peltate leaves of Philcoxia minensis. The shallow layer of sand grains which naturally covers the leaves was removed to take this photograph.

that Philcoxia might be carnivorous, most botanists who have examined herbarium specimens of these plants have speculated about carnivory in this genus, but conclusive evidence could not be gathered. A first test for carnivory conducted on Philcoxia minensis on living greenhouse-grown plants showed negative results (Fritsch et al. 2007), however only the very simple photo-film test method was applied, and negative results have also been gained in their experimental setup for the well-known, doubtlessly carnivorous plant Pinguicula. Subsequently a more detailed study showed compelling evidence for carnivory in Philcoxia: Pereira et al. (2012) gained positive results for enzyme activity in the leaf glands of Philcoxia minensis (by a phosphatase activity test), and the even more convincing isotope tracing experiments of the same study demonstrate the uptake of nitrogen originating from the nematode prey into the plant tissue directly. Nematodes from lab-cultures that were fed with heavy nitrogen $\left({ }^{15} \mathrm{~N}\right)$ were applied to the glandular leaves of Philcoxia minensis plants under controlled conditions of a greenhouse. After only 1-2 days (a time-frame we would call "prey digestion time" in the more well-known sticky-leaved carnivorous plants, like Drosera or Pinguicula), the nematodes were dead and a significant amount of the heavy nitrogen could already be found in the plant tissue. This means that the nematodes had to be digested by the plant (the enzyme activity of the leaf glands was also verifiably shown by Pereira et al. 2012), and that the nutrients released from the prey were absorbed by the leaves (natural organic decomposition of the nematodes, e.g. by soil bacteria, can likely be excluded in such a short time; moreover nematodes have a robust chitin exoskeleton, which has to be enzymatically cracked open -like in the common insect prey of "bigger" carnivorous plants- in order to release their soluble nutrient content). And even if we would find out that it was not the plant glands who finally digested the caught 

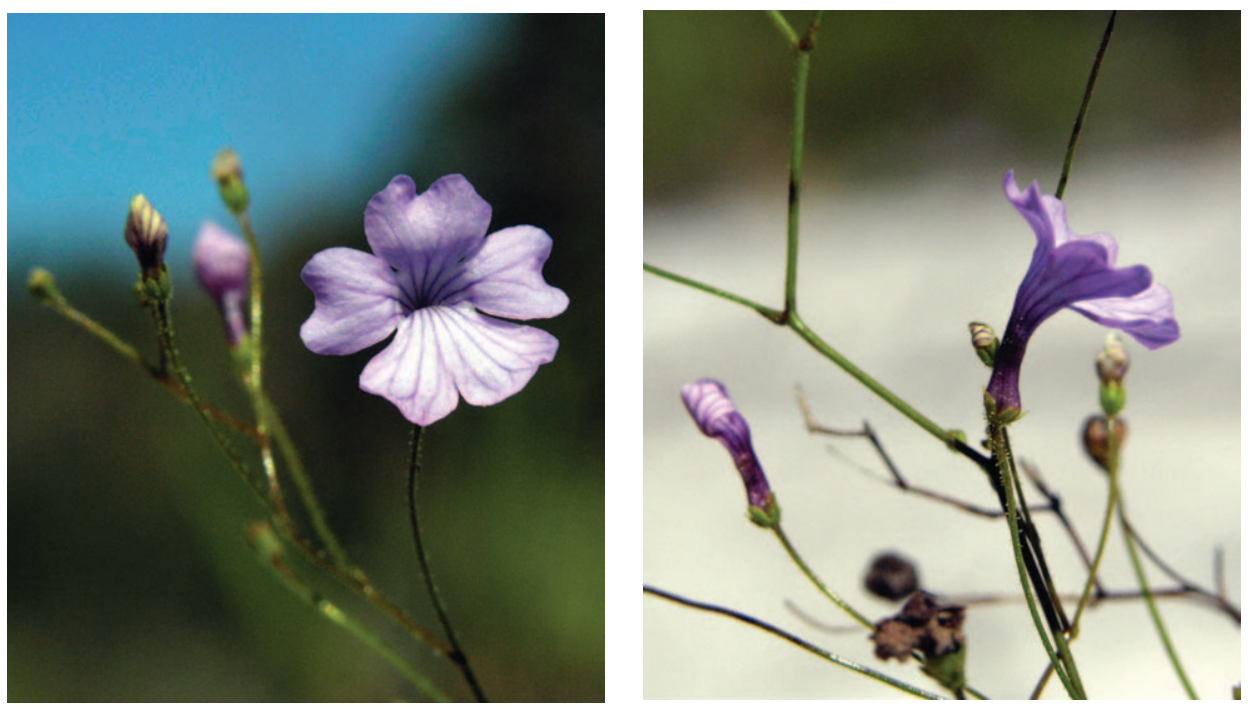

Figure 2: Close-up of the purple flowers of Philcoxia minensis, which are about $5 \mathrm{~mm}$ in diameter.

nematodes, but associated bacteria, this does not mean that the carnivorous nature of Philcoxia has to be questioned: Ellis \& Midgley (1996) demonstrated the digestive mutualism of the enzyme-lacking carnivorous plant Roridula in the very same way, by applying nitrogentraced Drosophila flies to Roridula leaves. After a few days, an impressive amount of the nitrogen isotopes was already found incorporated into the Roridula leaves, after it has been sucked from the flies by the associated Pameridea bugs, which then deposited their heavy nitrogen enriched faeces on the plant leaves, where it was absorbed from specialized cells. If you will place isotope-traced insects on non-carnivorous sticky plants like Proboscidea, Ibicella, or tomatoes, however, barely any nutrients from that prey will be found in the plants. That makes the difference between a carnivorous plant like Philcoxia, and a non-carnivorous plant like Proboscidea.

Affinity of Philcoxia to other carnivorous plants

Although Philcoxia superficially resembles terrestrial members of Utricularia and Genlisea, and it indeed was initially thought to be an unknown member of Lentibulariaceae when the first specimens were collected in Brazil (Taylor et al. 2000), a closer examination of the plants revealed that this genus is not closely related with any of the "classic" carnivorous plant genera.

Philcoxia without any doubt belongs to the tribe Gratioleae of Plantaginaceae (the plantain family, part of which formerly was included in the figwort family Scrophulariaceae), as it is both evident from flower morphology (Taylor et al. 2000) and molecular phylogenetic data (Fritsch et al. 2007; Schäferhoff et al. 2010). The firm proof of Pereira et al. (2012) that Philcoxia is in fact carnivorous makes this the first carnivorous plants known from the Plantaginaceae family, and adds a new genus of carnivorous plants to our knowledge. This also means that carnivory has independently evolved at least three times in parallel in the large 


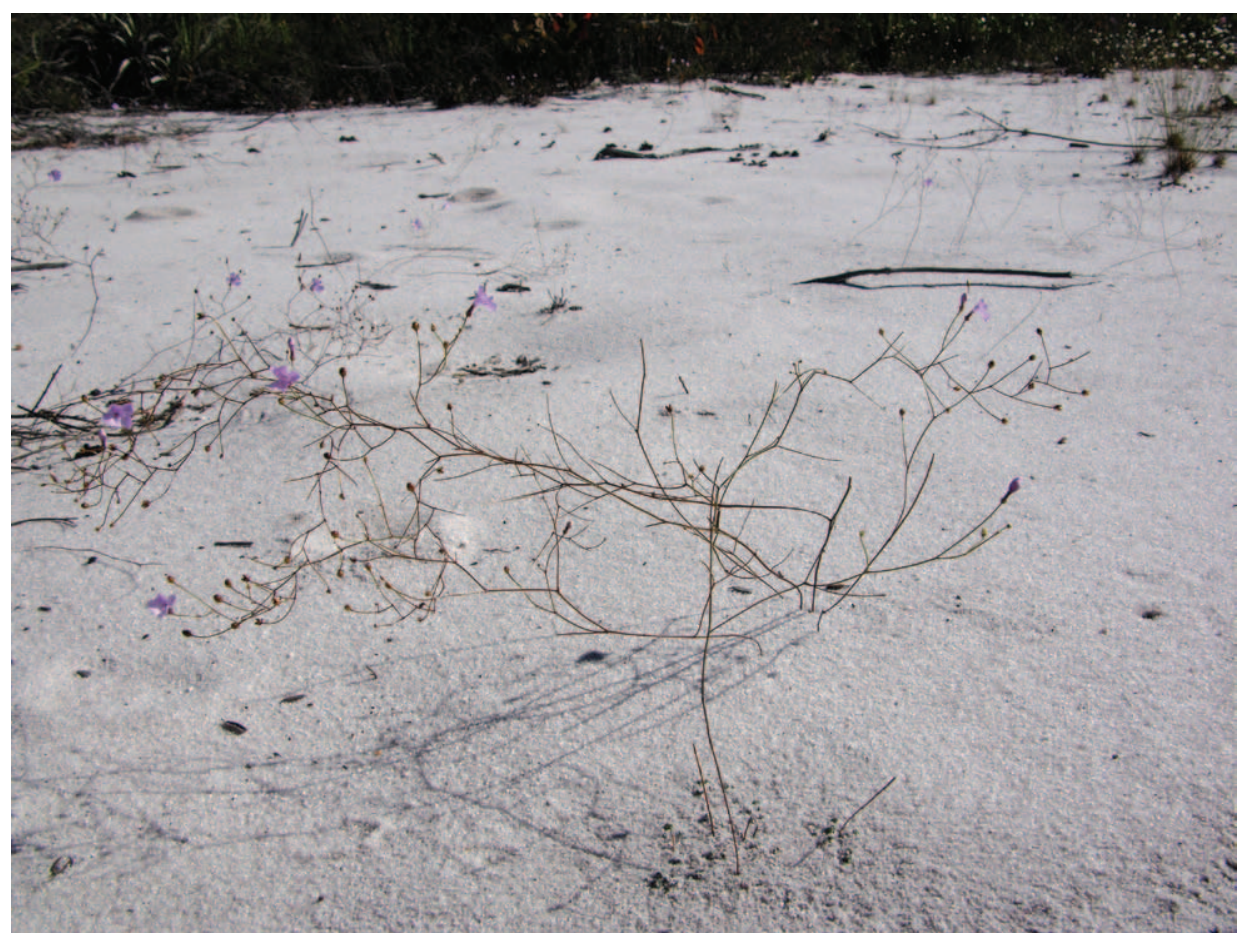

Figure 3: Philcoxia minensis in habitat in the Serra do Cabral, Minas Gerais state, Brazil. The plant grows in open plains of very dry, pure, fine quartzitic sand, accompanied only by a few cacti and annual Eriocaulaceae (in the background in the upper right).

order of dicotyledonous flowering plants, the Lamiales (the mint-allies), in only distantly related groups: namely in Philcoxia from the Plantaginaceae, in the carnivorous Lentibulariaceae (i.e. Pinguicula, Utricularia, and Genlisea), and in the even more distantly related Byblis from the Byblidaceae.

Considering the rare and endemic distribution of the three species of Philcoxia, as well as their fragile and complex natural sand habitat, which for obvious reasons will be very difficult to imitate artificially, it is not surprising that this genus of carnivorous plant is not likely to be widely cultivated by carnivorous plant enthusiasts in the near future. Long-term greenhouse cultivation of Philcoxia minensis proved to be difficult (P. Fritsch, pers. com.), and seeds of Philcoxia have not been successfully germinated yet (P. Fritsch, pers. com.; R. Oliveira pers. com.).

Acknowledgements: I would like to thank Rafael Oliveira, Caio Pereira, Peter Fritsch, Ray Harley, and Fernando Rivadavia for numerous inspiring discussions about Philcoxia biology and ecology.

\section{References}

Ellis, A.G., and Midgley, J.J. 1996. A new plant-animal mutualism involving a plant with sticky leaves and a resident hemipteran. Oecologia 106: 478-481.

Fritsch, P.W., Almeda, F., Martins, A.B., Cruz, B.C., and Estes, D. 2007. Rediscovery and phylo- 
genetic placement of Philcoxia minensis (Plantaginaceae), with a test of carnivory. PCAS 58: 447-467.

Pereira, C.G., and Oliveira, R.S. 2010. Philcoxia. In: McPherson, S., Carnivorous Plants and their Habitats. Redfern, Dorset: 1089-1103.

Pereira, C.G., Almenara, D.P., Winter, C.E., Fritsch, P.W., Lambers, H., and Oliveira, R.S. 2012. Underground leaves of Philcoxia trap and digest nematodes. PNAS 109: 1154-1158.

Schäferhoff, B., Fleischmann, A., Fischer, E., Albach, D.C., Borsch, T., Heubl, G., and Müller, K.F. 2010. Towards resolving Lamiales relationships: insights from rapidly evolving chloroplast sequences. BMC Evolutionary Biology 10: 352-374.

Taylor, P., Souza, V.C., Giulietti, A.M., and Harley, R.M. 2000. Philcoxia: a new genus of Scrophu-

lariaceae with three new species from Eastern Brazil. Kew Bulletin 55: 155-163.
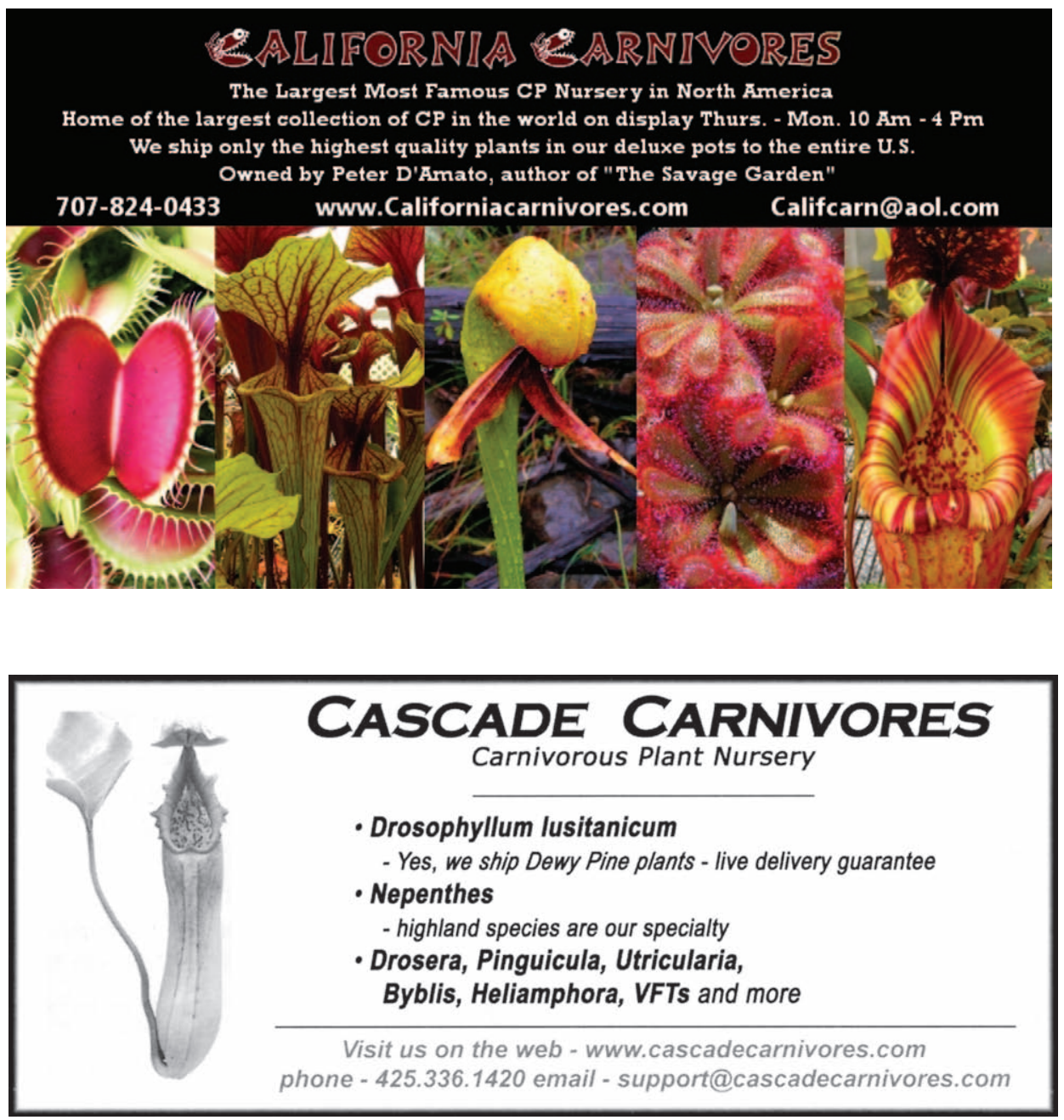